\title{
Localized Melanization of Appressoria Is Required for Pathogenicity of Venturia inaequalis
}

\author{
Ulrike Steiner and Erich-Christian Oerke
}

Institute of Crop Science and Resource Conservation, Phytomedicine, University of Bonn, Nussallee 9, D-53115 Bonn, Germany. Accepted for publication 17 April 2007.

\begin{abstract}
Steiner, U., and Oerke, E.-C. 2007. Localized melanization of appressoria is required for pathogenicity of Venturia inaequalis. Phytopathology 97:1222-1230.

During formation of appressoria produced from conidia and ascospores of Venturia inaequalis, a dark brown ring structure was detected at the base of appressoria. This melanized appressorial ring structure (MARS) was attached to the leaf surface like a sealing ring and formed the fungus-plant interface; it is believed to be required for pathogen penetration of the cuticle. Neither germ tubes nor infection structures beneath the cuticle were found to be visibly melanized. MARS were formed not

surfaces differing in hydrophobicity; the formation of appressoria and MARS was confined to hard surfaces. The melanin nature of the ring was confirmed by using melanin biosynthesis inhibitors. Applications prior to inoculation largely inhibited the melanization and reduced infection rate by 45 to $80 \%$; curative applications were not effective. Transmission electron microscopy verified a localized melanization of the cell wall around the penetration pore, and melanin was incorporated into all layers of the fungal cell wall. Appressoria without MARS were not able to infect the plant, suggesting that this structure can be considered to be a pathogenicity factor in $V$. inaequalis.
\end{abstract} only on apple leaves but also on leaves of nonhost plants and artificial
Additional keywords: apple scab.
Venturia inaequalis (Cooke) G. Winter is a hemibiotrophic ascomycetous fungus that causes scab disease in apple (Malus $\times$ domestica Borkh). It is present in most apple-growing regions of the world and currently is controlled by extensive use of fungicides (28). The asexual Spilocaea state of $V$. inaequalis bears blastic conidia on annellidic conidiophores (8). Environmental conditions (leaf wetness duration and temperature) required for ascospore production and infection of apple leaves have been studied extensively and are well documented $(27,29,32)$. Thus, environmental data can be used for disease prognosis and choosing appropriate times for fungicide application $(12,37,38)$.

With the exception of classical studies $(1,2,34,40,45,48)$, microscopic studies of the early infection process of the scab fungus are rare. $V$. inaequalis is a representative of a group of phytopathogenic fungi which form subcuticular hyphae and derive nutrients from the underlying host tissue. After germination of ascospores or conidia on the surface, the leaf cuticle is penetrated and subcuticular mycelia and stromata are established. The subcuticular development of $V$. inaequalis in leaves of apple cultivars varying in scab resistance (i.e., the formation of primary and secondary stromata, runner hyphae, and coralliphaerous hyphae) has been documented by light and electron microscopy $(8,13,35$, $45,46,47)$. Pathogenicity factors of this fungus are largely unknown. However, cell-wall-degrading enzymes and melanoproteins are thought to contribute to pathogenicity in the genus Venturia $(17,21,23,33)$.

In spite of the fact that the infection process, including appressorium formation, has been well studied, a melanized appressorial ring structure (MARS) has not yet been observed. Here, we report on microscopic studies involving melanin biosynthesis inhibitors

Corresponding author: U. Steiner; E-mail address: u-steiner@uni-bonn.de

doi:10.1094/PHYTO-97-10-1222

(c) 2007 The American Phytopathological Society
(MBIs) and melanin precursors to investigate the role of MARS in the infection process of the apple scab fungus.

\section{MATERIALS AND METHODS}

Plant material. Apple (Malus domestica L.) plants grown from pregerminated seed (cv. Golden Delicious) were used for inoculation experiments when three leaves were fully expanded. Leaves of wheat (Triticum aestivum L., cv. Kanzler), grapevine (Vitis vinifera L., cv. Müller Thurgau), and pea (Pisum sativum L., cv. Rondo) were used for inoculation at growth stages (GSs) (31) 13 (wheat) and 15 to 17 (grapevine and pea), respectively.

Pathogen. Three strains of $V$. inaequalis collected at Bonn, Germany (strain H1), Jork, Germany (N5), and Basle, Switzerland (N1) were cultivated on susceptible leaves of apple cv. Golden Delicious until heavy sporulation. Diseased leaves were sampled and immediately frozen at $-20^{\circ} \mathrm{C}$. To harvest conidia for inoculation experiments, diseased leaves were rinsed with tap water $(+0.01 \%$ Tween 80$)$ (Merck-Schuchardt, Hohenbrunn, Germany), the spore suspension was filtered through two layers of cheesecloth, and the spore concentration was adjusted to $10^{5}$ spores $\mathrm{ml}^{-1}$. After spray inoculation, plants were incubated at 20 to $22^{\circ} \mathrm{C}$ and $100 \%$ relative humidity (RH) for $48 \mathrm{~h}$. Subsequently, plants were grown under greenhouse conditions at 50 to $70 \%$ RH. Disease severity on apple leaves was assessed 14 to 16 days postinfection (dpi) as percentage of the upper two leaves displaying typical leaf scab symptoms (= sporulating leaf area, $n=15$ ).

For experiments on appressorium formation on artificial surfaces, glass microscope slides (Marienfeld, Lauda-Königshofen, Germany), polystyrene (petri dishes; Greiner Bio-one, Frickenhausen, Germany) and polytetrafluoroethylene (PTFE) (0.05-mm thickness; Labo-Tech International, Weil am Rhein, Germany) on glass slides, a cellulose layer on glass slide, and water agar (2\%; Sigma-Aldrich, Taufkirchen, Germany) were sprayed with spore suspensions. 
Fungicides and melanin biosynthesis precursors. The MBI fungicides carpropamid (Bayer CropScience, Monheim, Germany), fenoxanil (BASF AG, Ludwigshafen, Germany), pyroquilon (Pestanal; Sigma-Aldrich, Seelze, Germany), and tricyclazole (Dow Agro Sciences Ltd., Norfolk, UK) were used as technical compounds prepared as aqueous solutions at $250 \mu \mathrm{g} \mathrm{m}^{-1}$ in $0.03 \%$ non-ionic emulgator NP15 $+1 \mathrm{ml}$ of acetone. Trifloxystrobin (Flint, 50\% a.i.; Bayer CropScience) was used at $50 \mu \mathrm{g} \mathrm{ml}^{-1}$. 1,8-Dihydroxynaphthalene (DHN; Fluka AG, Buchs, Switzerland) was applied at $100 \mu \mathrm{M}$ in $0.03 \%$ NP15. Apple leaves were sprayed either pre- or post infection until run-off.

Light microscopic investigations. For Nomarski interference microscopy, leaflets were fixed and discolored in saturated chloral hydrate (250 g in $100 \mathrm{ml}$ of Aqua dest.). For fluorescence microscopy, leaf discs taken $12,24,36$, and 48 h postinoculation (hpi) were cleared in ethanol/chloroform/acetic acid (6:3:1), softened in $1 \mathrm{~N} \mathrm{KOH}\left(1 \mathrm{~h}\right.$ at $\left.60^{\circ} \mathrm{C}\right)$, rinsed in $0.067 \mathrm{M} \mathrm{K}_{2} \mathrm{HPO}_{4}(\mathrm{pH} 9.0)$, and stained in $0.1 \%(\mathrm{wt} / \mathrm{vol})$ aniline blue in $0.067 \mathrm{M} \mathrm{K}_{2} \mathrm{HPO}_{4}$ as described (35). Specimens were examined with a DMRB Leica microscope (Leitz, Wetzlar, Germany) equipped with filter block A (BP 340-380 nm, LP $425 \mathrm{~nm}$ ) for fluorescence techniques. Azure A was used for melanin-specific staining according to Butler and Lachance (6).

Transmission electron microscopy. Samples ( 2 by $4 \mathrm{~mm}^{2}$ ) were excised from inoculated leafs $24 \mathrm{hpi}$ and immediately placed in fixing solution $(8 \%$ [vol/vol] formaldehyde, $8 \%$ [vol/vol] glutaraldehyde, and $0.2 \mathrm{M} \mathrm{Na-cacodylate} \mathrm{buffer}[1: 1: 2 \mathrm{vol} / \mathrm{vol} / \mathrm{vol}]$ containing $\mathrm{CaCl}_{2}$ at $0.005 \mathrm{~g} \mathrm{liter}^{-1}$ ) overnight at room temperature. The samples were washed (five times for $10 \mathrm{~min}$ each) in $0.2 \mathrm{M} \mathrm{Na}$-cacodylate buffer at $\mathrm{pH} 7.3$ and post-fixed in osmium tetra-oxide $\left(\mathrm{OsO}_{4}\right)$ fixing solution $\left[0.4 \%\right.$ [vol/vol] $\mathrm{KCr}_{2} \mathrm{O}_{7}, 3.4 \%$ [vol/vol] $\mathrm{NaCl}$, and $2 \%$ [vol/vol] $\mathrm{OsO}_{4}$ [1:1:2 vol/vol]) for at least $2 \mathrm{~h}$. After washing with Na-cacodylate buffer (eight times for 20 min each), samples were dehydrated in a graded series of alcohol, rinsed in propylene oxide, infiltrated with increasing concentration of Spurr's ERL-resin (10 g of ERL-4206, $4 \mathrm{~g}$ of DER-736, and $0.4 \mathrm{~g}$ of S-1) (Agar Aids, Marburg, Germany) before being embedded in ERL-resin at $70^{\circ} \mathrm{C}$ for 8 to $12 \mathrm{~h}$. Sectioning was carried out on a Reichert Jung Ultracut E microtome (Heidelberg, Germany) using glass or diamond knives. Penetration sites were identified from $0.5-\mu \mathrm{m}$-thick semithin sections stained with $0.1 \%$ ( vol/vol) toluidine blue under a light microscope; then, ultrathin sections were cut for electron microscopy. The ultrathin sections were contrasted using uranyl acetate and lead acetate before being observed with an electron microscope (EM 109; Zeiss, Oberkochen, Germany).

Quantitative assessment of melanization intensity. Dots $(5 \mu \mathrm{l}$ each) of a spore suspension $\left(\approx 80,000\right.$ conidia $\mathrm{ml}^{-1}$, four dots per treatment) were spotted on a translucent polystyrene plate $(2 \mathrm{~mm}$ thick) and were incubated in a moist $(100 \% \mathrm{RH})$ chamber at $20^{\circ} \mathrm{C}$ for $36 \mathrm{~h}$. After $0,4,6,8,10$, and $12 \mathrm{~h}$ of incubation, $5 \mu \mathrm{l}$ of a solution containing the melanin biosynthesis inhibitor carpropamid at $250 \mu \mathrm{g} \mathrm{ml}^{-1}$ (in $0.03 \%$ non-ionic emulgator NP15 $+1 \mathrm{ml}$ of acetone per $100 \mathrm{ml}$ of water) was added; control dots received only the formulation without active ingredient (formulation blank). After $36 \mathrm{~h}$, the plates were rinsed twice with tap water in order to remove all soluble substances, carefully air dried, and scanned. Using the image analysis software ASSESS (The American Phytopathological Society, St. Paul, MN), the extent of melanization of the spots was quantified. In another set of experiments, carpropamid was removed from the germinating conidia by rinsing the plates after 12 and $24 \mathrm{~h}$ of incubation. After rinsing, spores were incubated with $10 \mu \mathrm{l}$ of tap water and incubated at $100 \% \mathrm{RH}$ and $20^{\circ} \mathrm{C}$ for up to $48 \mathrm{~h}$.

Data analysis. Data were analyzed by standard analysis of variance using the GLM procedure (SAS vers. 8.0; SAS Institute Inc., Cary, NC). When $F$ values were significant, the mean comparisons were performed with the significant difference value at the level of $P \leq 0.05$. All experiments were conducted at least twice.

\section{RESULTS}

Germination of conidia and appressorium formation on apple leaves. Spray-inoculated conidia of $V$. inaequalis germinated under the experimental conditions within $6 \mathrm{hpi}$. The hyaline germ tube was formed at the tip of single-celled conidia and grew on the leaf surface without branching. At $\approx 6$ to $8 \mathrm{hpi}$, the tip of the germ tube began to swell and produced an appressorium, typically above an anticlinal cell wall of the epidermal layer (Fig. 1A). The penetration peg penetrated the plant cuticle 12 to $16 \mathrm{hpi}$; subsequently, the pathogen established a hyaline primary stroma between cuticle and cell wall of epidermal cells (Fig. 1B). During appressorium development, a dark brown ring structure was formed at the leaf-facing side of appressoria, attached to the cuticle like a sealing ring (O-ring) (Fig. $1 \mathrm{~B}$ and $\mathrm{C}$ ). This structure was detected more easily in fluorescence than in interference microscopy (Fig. 1D, arrow). The dark brown ring structure had an outer diameter of $\approx 3 \mu \mathrm{m}$ surrounding an appressorial pore of $\approx 0.7$ to $1.0 \mu \mathrm{m}$ in diameter and formed the interface between the fungus and host plant (Fig. 1E). Neither germ tubes nor infection structures beneath the plant cuticle were found to be darkly pigmented (Fig. 1). Using aniline blue staining and fluorescence microscopy, the MARS was visible also during later stages of leaf colonization (Fig. 1G, arrow).

Formation of appressoria from conidia on various surfaces. On artificial surfaces, the germination rate of $V$. inaequalis was slightly higher than on leaves of different plant species (Table 1). Germinating conidia produced appressoria on all hard surfaces tested, regardless of their morphology and chemical composition. No differences were observed between the three isolates under investigation. On the soft surface of $2 \%$ water agar, the conidia formed extremely long germ tubes; however, they failed to produce appressoria. Appressoria were formed on the leaf surface of the nonhost plants wheat, grapevine, and pea as well as on artificial surfaces differing in physical characteristics and chemical composition-the rate of appressorium formation on nonhost leaves and cellulose was significantly lower than on apple leaves and hard artificial surfaces. All appressoria formed on the various surfaces showed a typical dark-pigmented ring structure at the interface of appressorium and surface surrounding the appressorial pore (Fig. 2A to F).

Formation of appressoria from ascospores. On glass slides, the appressorium formation of ascospores of $V$. inaequalis was very similar to that of germ tubes produced by conidia (Fig. 3A and $\mathrm{B}$ ). The characteristic $\mathrm{O}$-ring between appressorium and surface had dimensions similar to those produced on apple surfaces. In some cases, a tapered hyphae was formed at the tip of the MARS-bearing appressorium (Fig. 3C). Staining with azure A provided some evidence for the melanin character of the O-ring at the surface-appressorium interface (Fig. 3D and E).

Ultrastructural MARS localization. Transmission electron microscopy images confirmed the localized melanization of $V$. inaequalis appressorial cell walls at the appressorium-substratum interface (Fig. 4). In contrast to the generally electron-transparent cell wall of appressoria, all layers of the cell wall around the penetration pore were electron-dense indicating strong melanization (Fig. 4A and D). At this site, the appressorial cell wall was tapered and disappeared completely at the penetration pore (Fig. 4B). The infection sac within the appressorium proved to be nonmelanized.

Effect of MBI fungicides on MARS. In vivo experiments. The MBI fungicides applied before the inoculation of apple leaves with conidia of $V$. inaequalis inhibited the formation of dark brown sealing rings and reduced infection by 45 to $80 \%$ (Table 2). Carpropamid, an inhibitor of scytalon dehydratase, gave better control than the naphthol reductase inhibitors pyroquilon and tri- 
cyclazole; however, its efficacy was significantly lower than that of the strobilurin trifloxystrobin, which reached $99 \%$ disease control. Applications of MBIs after the penetration of the cuticle by $V$. inaequalis were not effective-in contrast to trifloxystrobin, which effectively controlled also the early subcuticular development of the pathogen (Fig. 5).

On untreated leaves, almost $90 \%$ of germ tubes produced an appressorium with a MARS, resulting in a frequency of cuticle

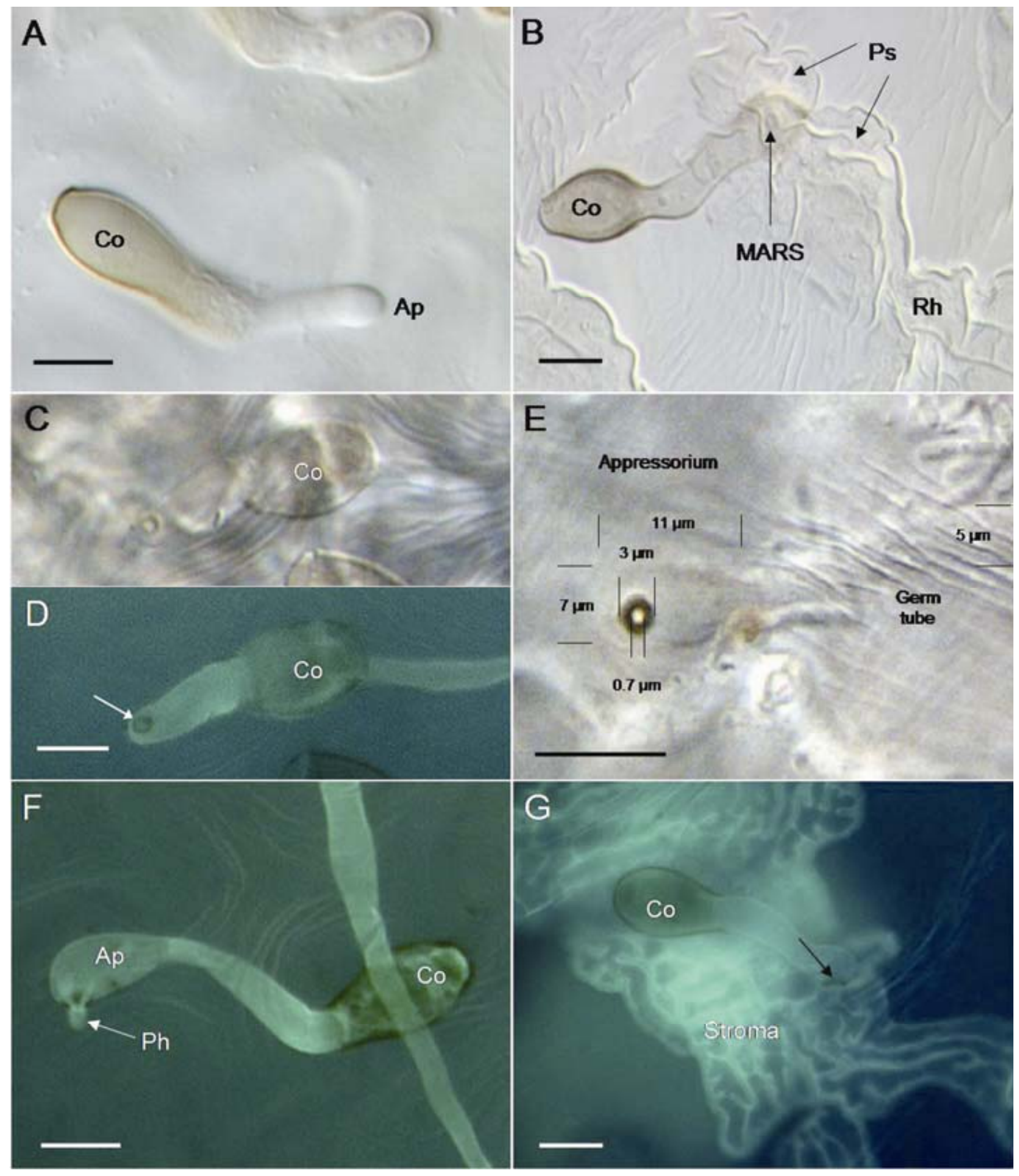

Fig. 1. Formation of a melanized appressorial ring structure (MARS) by Venturia inaequalis on apple leaves. A, B, C, and E, Visualization of MARS at the interface of appressorium and leaf surface using interference; and $\mathbf{D}, \mathbf{F}$, and $\mathbf{G}$, fluorescence microscopy after staining with aniline blue. A, Formation of appressorium (Ap) on anticlinal cell wall $6 \mathrm{~h}$ postinoculation; B, subcuticular primary stroma (Ps) and runner hyphae (Rh) under an infection site with MARS; detection of MARS under appressorial tip using $\mathbf{C}$, interference and $\mathbf{D}$, fluorescence microscopy, respectively; $\mathbf{E}$, dimensions of appressorium and MARS; $\mathbf{F}$, the penetration hypha $(\mathrm{Ph})$ is formed through MARS; and $\mathbf{G}$, visible melanization is restricted to the conidium (Co) and the ring structure at the bottom of the appressorium. Bars represent $10 \mu \mathrm{m}$. 
penetration of $81 \% 72 \mathrm{~h}$ after inoculation; only $5 \%$ of the appressoria had no MARS (Table 3). In the presence of carpropamid applied $3 \mathrm{~h}$ before inoculation, the rate of appressorium formation (percentage of germinated conidia) was markedly reduced and only very few appressoria produced a MARS. In all, $\approx 25 \%$ of these appressoria formed a nonmelanized ring structure tightly appressed to the leaf surface. The inhibition of melanin biosynthesis was associated with a significant increase in germ tube length and reduced the penetration rate per conidium by $>90 \%$.

Furthermore, fluorescence microscopy after aniline blue staining allowed very sensitive MARS detection, but revealed no evidence for the formation of a MARS (Fig. 6A and B). Most germ tubes were able to produce an appressorium intimately

TABLE 1. Formation of early infection structures of Venturia inaequalis on different surfaces after incubation for $36 \mathrm{~h}$ at $20^{\circ} \mathrm{C}$ and $100 \%$ relative humidity ${ }^{\mathrm{x}}$

\begin{tabular}{lcccc}
\hline & $\begin{array}{c}\text { Germination } \\
\text { rate }(\%)\end{array}$ & $\begin{array}{c}\text { Germ tube } \\
\text { length }(\mu \mathrm{m})\end{array}$ & $\begin{array}{c}\text { Formation of } \\
\text { appressoria } \\
(\%)\end{array}$ & $\begin{array}{c}\text { Formation } \\
\text { of MARS } \\
(\%)^{\mathrm{y}}\end{array}$ \\
\hline Apple leaves & $86.0 \mathrm{abc}$ & $17.4 \mathrm{e}$ & $82 \mathrm{a}$ & $81 \mathrm{a}$ \\
Grapevine leaves & $80.0 \mathrm{c}$ & $19.4 \mathrm{de}$ & $65 \mathrm{bc}$ & $63 \mathrm{bc}$ \\
Pea leaves & $86.0 \mathrm{abc}$ & $28.9 \mathrm{cde}$ & $55 \mathrm{c}$ & $53 \mathrm{c}$ \\
Wheat leaves & $79.0 \mathrm{c}$ & $40.2 \mathrm{c}$ & $59 \mathrm{c}$ & $51 \mathrm{~cd}$ \\
Glass slide & $91.0 \mathrm{ab}$ & $36.8 \mathrm{cde}$ & $80 \mathrm{ab}$ & $79 \mathrm{ab}$ \\
Polystyrene & $94.0 \mathrm{a}$ & $27.2 \mathrm{cde}$ & $89 \mathrm{a}$ & $88 \mathrm{a}$ \\
PTFE on glass slide & $93.0 \mathrm{a}$ & $39.4 \mathrm{~cd}$ & $83 \mathrm{a}$ & $80 \mathrm{ab}$ \\
Cellulose on glass slide & $84.0 \mathrm{bc}$ & $77.4 \mathrm{~b}$ & $36 \mathrm{~d}$ & $33 \mathrm{~d}$ \\
Water agar $(2 \%)$ & $92.0 \mathrm{ab}$ & $274.1 \mathrm{a}$ & 0 & 0 \\
\hline
\end{tabular}

$\mathrm{x}$ Values followed by the same letter are not significantly different (Tukey test, $P \leq 0.05)$.

y MARS = melanized appressorial ring structure.

${ }^{z}$ PTFE = polytetrafluoroethylene.
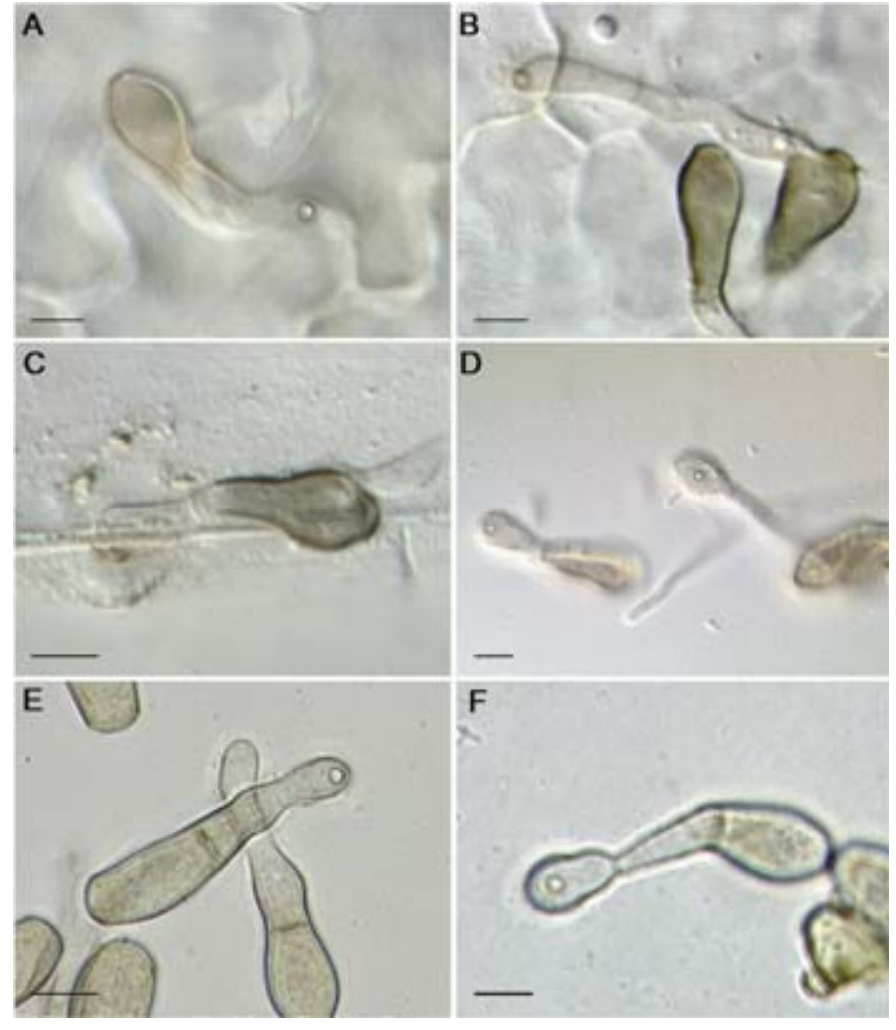

Fig. 2. Formation of melanized appressorial ring structure by Venturia inaequalis on different surfaces: $\mathbf{A}$, apple leaf (natural host); B, grapevine leaf; C, wheat leaf; D, glass (note the same z-focus of MARS from both appressoria); E, polystyrene; and $\mathbf{F}$, polytetrafluoroethylene. Images were taken after $24 \mathrm{~h}$ of incubation under ambient conditions. attached to the leaf cuticle (Fig. 6A). Neither MARS formation nor the penetration of the apple cuticle could be observed for these appressoria. In all, $\approx 20$ to $30 \%$ of germinated conidia formed extended germ tubes which often were tapered after the first attempt to form an appressorium (Fig. 6B).

The complementation of the melanin biosynthesis pathway with DHN, one of the last precursors before melanin polymerization, after $10 \mathrm{~h}$ of incubation in the presence of carpropamid resulted in a complete restoration of fungal pathogenicity (Fig. 7). The application of DHN and carpropamid $3 \mathrm{~h}$ before the start of incubation was not effective. DHN alone proved to increase disease severity only when applied during the stage of appressorial development.

In vitro experiments. On polystyrene, $\approx 90 \%$ of germinated conidia produced appressoria with a dark O-ring within $48 \mathrm{~h}$. The ring was formed at the distal tip of appressorial part of the germ tube most of the time. Some O-rings, however, were located beneath the center of the appressorium (Fig. 6D). Carpropamid did not affect the germination of $V$. inaequalis conidia. However, in contrast to the slightly colored germ tubes produced from untreated conidia, germ tubes formed in the presence of the MBI were almost hyaline (the pigmentation of conidia was not affected) (Fig. 6E). Although appressoria were formed at a similar time and frequency, no melanized O-rings could be detected after MBI treatments. Similar to the development on apple leaves, the germ tubes often were longer on MBI-treated than on untreated surfaces. The base of the appressoria forming the interface between fungus and substratum was appressed to the polystyrene or glass surface in a way similar to that for untreated appressoria. In some instances, a nonmelanized ring structure was detected (Fig. 6F).

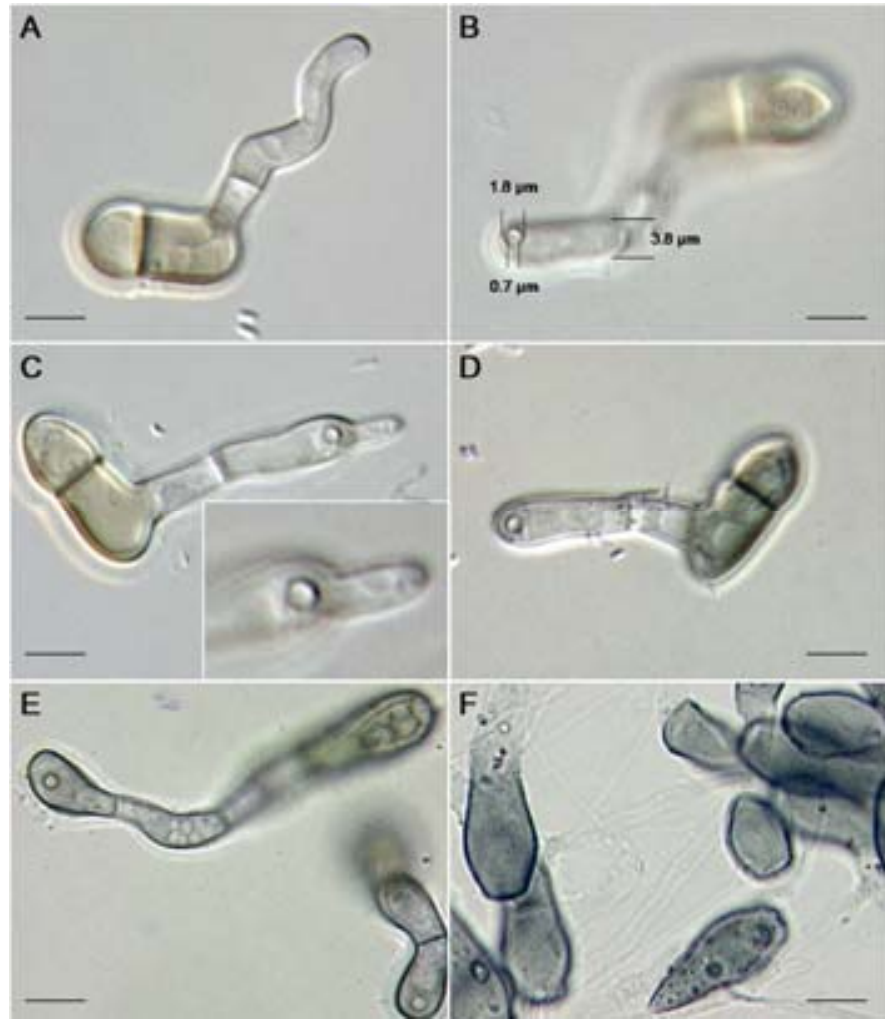

Fig. 3. A to C, Formation of melanized appressorial ring structure (MARS) by germ tubes produced by ascospores of Venturia inaequalis on a glass surface. A, Germ tube with first visible vesicle at the tip (after $22 \mathrm{~h}$ of incubation); B, dimensions of hypha and MARS (after $60 \mathrm{~h}$ of incubation); $\mathbf{C}$, the tip of the germ tube produces a narrow hypha (after $60 \mathrm{~h}$ of incubation). D to F, Azure A staining of fungal melanin. D, Germinated ascospore; $\mathbf{E}$, conidia on a grapevine leaf; and F, a glass surface sprayed with the melanin biosynthesis inhibitors fungicide carpropamid. 
The extent of pigmentation of germinated spores after $36 \mathrm{~h}$ of incubation was significantly reduced when MBIs were applied before the formation of appressoria started after $\approx 8 \mathrm{~h}$ of incubation (Fig. 8); when applied after appressorium formation had been completed by most of the germ tubes after $12 \mathrm{~h}$ of incubation, the effect of the MBI on pigmentation was insignificant. Because of the fixation of appressoria - with or without MARSto polystyrene surfaces, it was possible to limit the period of MBI incubation for germinating $V$. inaequalis spores in order to assess the critical period of appressorial melanin formation. The period of appressorium initiation and differentiation after 6 to $12 \mathrm{~h}$ of incubation proved to be most sensitive (Fig. 9). Microscopic investigations after $36 \mathrm{~h}$ demonstrated that an MBI application after $10 \mathrm{~h}$ of incubation resulted in the production of some MARS with a melanization of the ring less pronounced than for untreated appressoria. Without MBI, the intensity of melanization increased until the stage of completing appressorial development.

\section{DISCUSSION}

The penetration of intact apple cuticles by $V$. inaequalis is the prerequisite for nutrient uptake and subcuticular parasitic development of the fungus; it largely depends on the formation of melanin in the appressoria affixed to the cuticle, making melanin a pathogenicity factor of $V$. inaequalis. The formation of appressoria and the associated MARS occurred on various plant and artificial surfaces and obviously required no host plant-specific signal. On the soft surface of water agar, however, the formation of appressoria was not induced and germ tubes were extremely long, indicating that surface hardness is a trigger of appressorium

TABLE 2. Efficacy of the preventive application of various melanin biosynthesis inhibitors on the intensity of apple scab on apple leaves compared with the strobilurin trifloxystrobin

\begin{tabular}{lcc}
\hline Treatment $^{\mathrm{w}}$ & Diseased area $(\%)^{\mathrm{x}}$ & Efficacy $(\%)$ \\
\hline Untreated control $^{\mathrm{x}}$ & $55.3 \mathrm{a}$ & $\ldots$ \\
Carpropamid $^{\mathrm{y}}$ & $8.3 \mathrm{c}$ & 84 \\
Pyroquilon $^{\mathrm{y}}$ & $22.7 \mathrm{bc}$ & 58 \\
Tricyclazole $^{\mathrm{y}}$ & $30.1 \mathrm{~b}$ & 44 \\
Trifloxystrobin $^{\mathrm{z}}$ & $0.4 \mathrm{~d}$ & 99 \\
\hline
\end{tabular}

${ }^{\mathrm{w}}$ Fungicide application $2 \mathrm{~h}$ before inoculation and disease assessment 12 days after inoculation.

${ }^{x}$ Diseased leaf area $=$ percentage of total leaf area. Values with the same letter are statistically not significantly different (Kruskal-Wallis $\mathrm{H}$ test, $P \leq 0.05$ ).

y Application rate $250 \mu \mathrm{g} \mathrm{liter}^{-1}$.

$\mathrm{z}$ Application rate $50 \mu \mathrm{g}$ liter $^{-1}$.
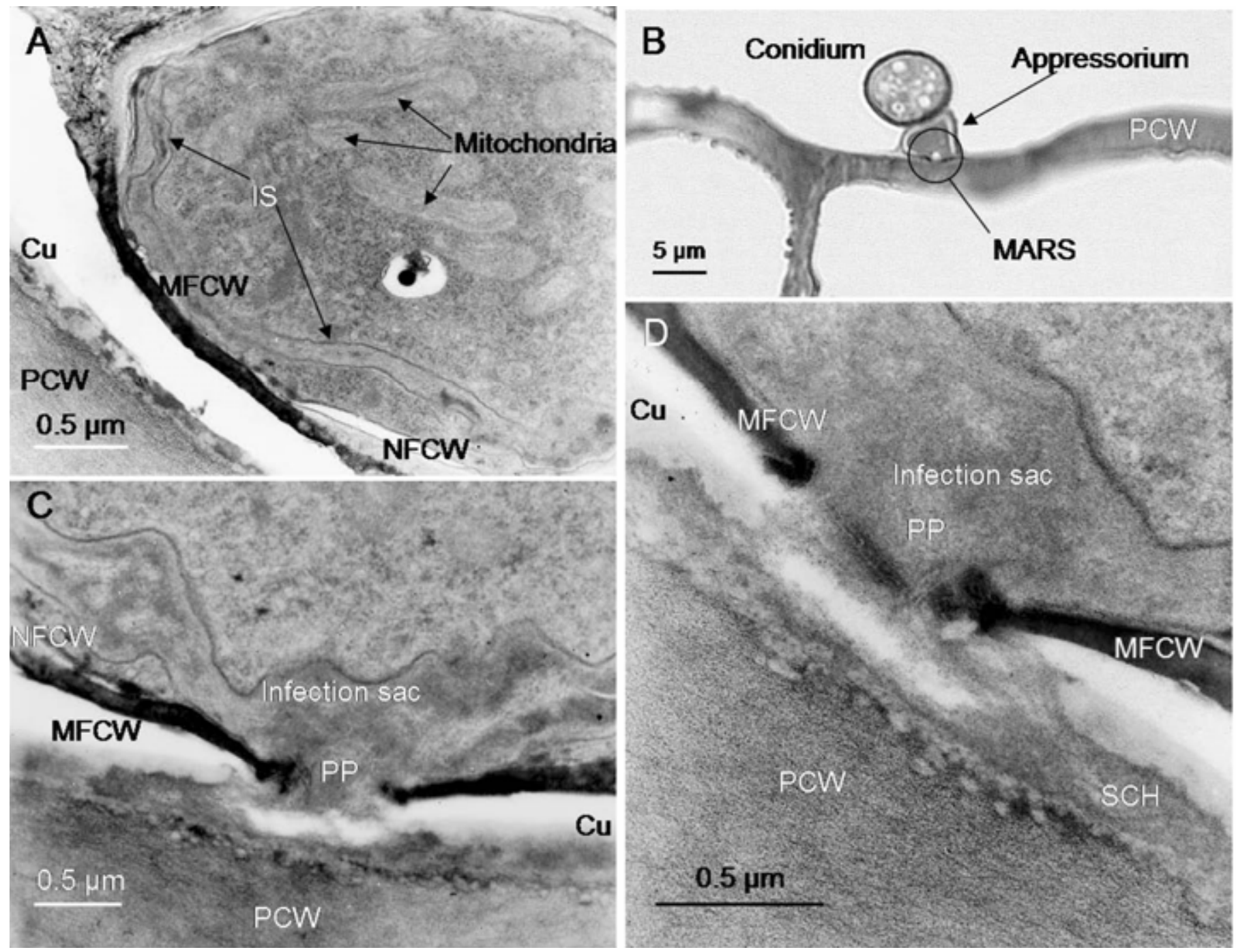

Fig. 4. Melanization of the appressorial cell wall of Venturia inaequalis forming the interface between pathogen and plant cuticle $24 \mathrm{~h}$ postinoculation in $\mathbf{A}$, C, and $\mathbf{D}$, transmission electron microscopy and $\mathbf{B}$, semithin section. Complete melanization of fungal cell wall (MFCW) at the interface. A, Note nonmelanized lateral parts of fungal cell wall (NFCW) (section of appressorium adjacent to the central penetration pore); B, melanized appressorial ring structure (MARS) formation between appressorium and plant cell wall (PCW); C, section of appressorium through MARS in the center of the penetration pore (PP); and D, close up of infection site with plant cuticle $(\mathrm{Cu})$ and subcuticular hypha $(\mathrm{SCH})$. IS, infection sac. 
formation which was associated with MARS formation. The significance of surface hardness was emphasized by preferential formation of appressoria above anticlinal cell walls of plants.

$V$. inaequalis has been characterized as a dark-pigmented ascomycetous fungus with an electron-translucent inner layer and an electron-dense outer layer of the cell walls of ascospores and hyphae, which may resemble dark granules of melanin $(4,40)$. On apple leaves, the strongly melanized conidia produce almost hyaline germ tubes which, in general, form light apical appressoria. The MARS produced by both germ tubes formed from ascospores as well as from conidia may become visible more easily by using fluorescence techniques; otherwise, the tiny structure may be obscured by other details.

More than 30 years ago, the mycelium of $V$. inaequalis has been shown to produce melanin. However, its role in the interaction of the apple scab fungus with its host plant has remained obscure. Under artificial conditions in liquid media, the fungus excretes a dark-brown protein which was reported to contain melanin $(16,18)$. Melanins are darkly pigmented polymers that protect organisms from environmental stress (14) and are considered to play an important role in longevity and survival of fungal spores and mycelia in nature, as described for Alternaria alternata (39). Phytopathogenic fungi such as Magnaporthe grisea and Colletotrichum spp. that produce melanized appressoria for host invasion require appressorial melanogenesis for pathogenicity $(24,49,50)$. Other fungi with darkly pigmented conidia, such as A. alternata, produce colorless appressoria. Tanabe et al. (42) showed that melanin probably is not relevant to pathogenicity of the Japanese pear pathotype of A. alternata. In contrast, conidia of Magnaporthe and Colletotrichum spp. are colorless and the

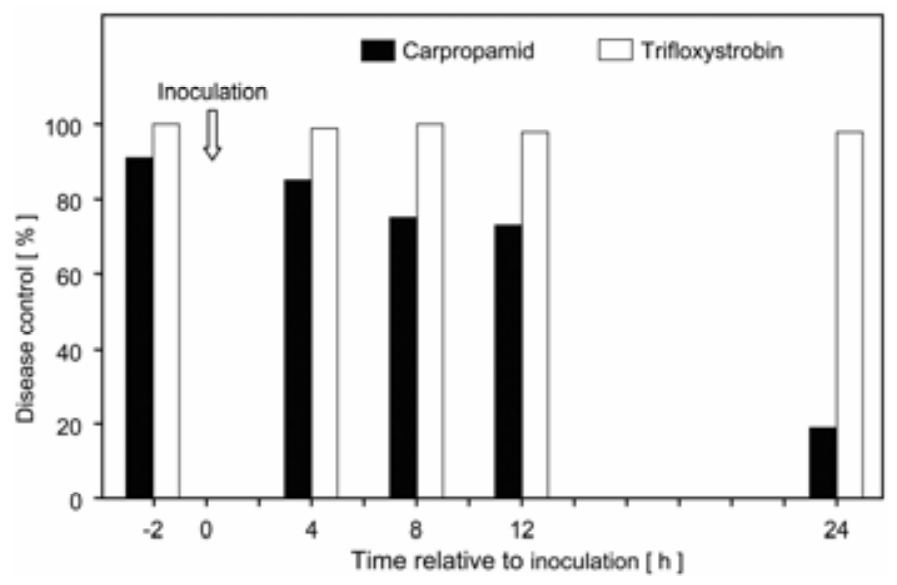

Fig. 5. Effect of time of application on the efficacy of the melanin biosynthesis inhibitor carpropamid against scab of apple leaves inoculated with Venturia inaequalis; comparison with the strobilurin fungicide trifloxystrobin (disease assessment 14 days after inoculation).

TABLE 3. Effect of the melanin biosynthesis inhibitor (MBI) carpropamid on appressorium formation on apple leaves after inoculation with Venturia inaequalis (isolate $\mathrm{N} 5)^{\mathrm{w}}$

\begin{tabular}{lcc}
\hline Infection stage & Without MBI & With MBI \\
\hline Germ tube length $(\mu \mathrm{m})$ & $19.6 \pm 1.0$ & $50.8 \pm 6.3$ \\
Appressorium rate $(\%)^{\mathrm{x}}$ & $93.1 \pm 3.3$ & $73.6 \pm 5.0$ \\
MARS formation $(\%)^{\mathrm{x}}$ & $88.9 \pm 2.8$ & $1.4 \pm 1.4$ \\
& $\ldots$ & $19.4 \pm 3.5^{\mathrm{y}}$ \\
Appressoria without MARS $(\%)^{\mathrm{z}}$ & 4.5 & 98.1 \\
Penetration of cuticle $(\%)^{\mathrm{x}}$ & $80.6 \pm 2.8$ & $6.9 \pm 1.4$ \\
\hline
\end{tabular}

${ }^{\mathrm{w}}$ MBI treatment of leaves $3 \mathrm{~h}$ before inoculation and sampling $72 \mathrm{~h}$ postinoculation $(n=6)$; data shown are mean \pm standard error of the mean.

${ }^{x}$ Percentage of germinated conidia.

y Pale ring structure, no melanization.

${ }^{\mathrm{z}}$ MARS = melanized appressorial ring structure. Percent of appressoria. melanization of appressoria of these pathogens has been demonstrated to be associated with their potential to build up a high osmotic pressure required for the penetration process of the plant cell wall $(5,9,20)$.

The MARS formation in $V$. inaequalis seems to mark the reduction of melanization of fungal infection structures to an absolute minimum allowing the pathogen to enter the plant. For



Fig. 6. Effect of the melanin biosynthesis inhibitor carpropamid on the formation of the melanized appressorial ring structure of Venturia inaequalis on $\mathbf{A}$ and $\mathbf{B}$, apple leaves and $\mathbf{C}$ to $\mathbf{F}$, glass. A, Appressorium without melanized appressorial ring structure (MARS) appressed to the leaf surface, $24 \mathrm{~h}$ postinoculation (hpi); B, extended growth of germ tube with tapered tip, $24 \mathrm{hpi}$; MARS development on glass for untreated conidia after $\mathbf{C}, 8$ and $\mathbf{D}, 24 \mathrm{hpi}$; development on glass for conidia in the presence of carpropamid after $\mathbf{E}$, 8 and $\mathbf{F}, 24$ hpi (arrow indicates nonmelanized ring). $\mathbf{A}$ and $\mathbf{B}$, fluorescence microscopy after staining with aniline blue and $\mathbf{C}$ to $\mathbf{F}$, interference microscopy.

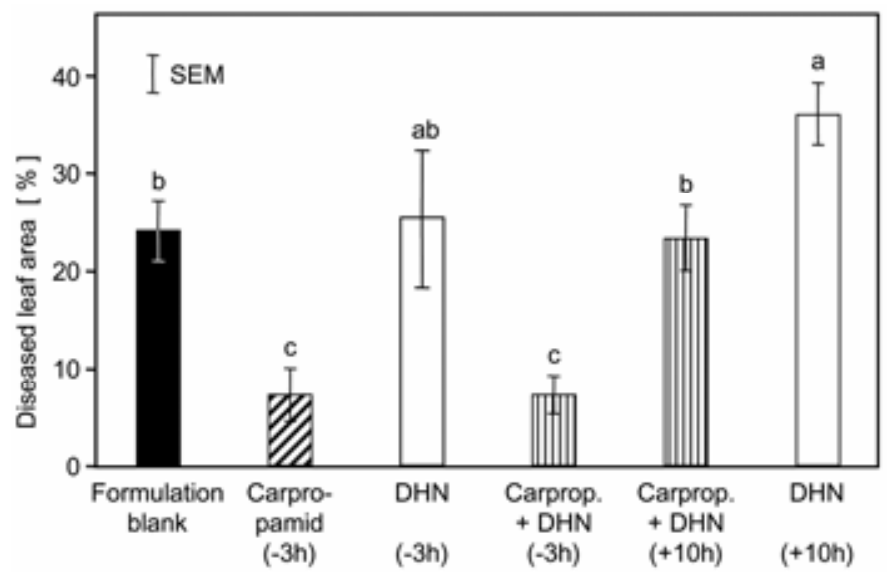

Fig. 7. Effect of the melanin precursor 1,8-dihydroxynaphthalene (DHN) on the pathogenicity of Venturia inaequalis in the presence of the melanin biosynthesis inhibitor carpropamid. DHN was sprayed on the apple leaf surface directly after carpropamid $3 \mathrm{~h}$ before inoculation with $V$. inaequalis spores or after $10 \mathrm{~h}$ of incubation; values followed by the same letter are not significantly different $(P \leq 0.05)$ based on Fisher's least significant difference test. 
$V$. inaequalis, entrance to the host plant is limited to penetration of the apple cuticle, allowing the uptake of nutrients from the plant and subcuticular growth of the pathogen. It is assumed that the force required to penetrate the cuticle is considerably lower than that for also penetrating the more rigid plant's cell wall, as described for $M$. grisea and Colletotrichum spp., which form appressoria with a cell wall melanized uniformly.

According to Corlett and Chong (7), the appressorium of $V$. inaequalis has a two-layered wall, a granular, electron-dense outer layer, and a granular, somewhat electron-transparent inner layer. At the base of the appressorium, the inner wall layer tapers off and disappears. In the middle of a circular, disk-like area of thickening, usually $\approx 6 \mu \mathrm{m}$ in diameter, is a circular, transparent, thin-walled, pore-like area $\approx 2 \mu \mathrm{m}$ in diameter (36). The appressorial pore is bordered by a slightly thickened outer wall layer which also tapers at the margin of the pore. The present study provides evidence that the appressorial pore is surrounded by a melanized ring structure forming the interface between appressorium and surface. As shown on plane model surfaces, MARS of appressoria formed by various conidia were localized in the very same z-focus directly on the base contacting the surface.

In $M$. grisea and Colletotrichum lagenarium, melanin is localized in the inner layer of the cell wall $(19,20,24)$ and, in other fungi and yeasts, as the outermost layer of the cell wall (14). Melanin in the appressorial cell wall of $V$. inaequalis was restricted to a ring structure surrounding the penetration pore. However, in contrast to other pathogenic fungi, all layers of the appressorial cell wall facing the substratum were completely melanized at this site. Ultrastructural images provide evidence for a higher density of melanin incorporation on the inner side of MARS arranged to the penetration pore. The localization of melanin in the appressorial cell wall of $V$. inaequalis has to be discussed with its potential functions in the infection process: adhesion to the plant's cuticle, increase of appressorial cell wall rigidity against penetration turgor of the pathogen, localization of fungal enzymes, or self-protection against hydrolytic activities. Melanization of the outer cell wall using extracellular dopamine $(2-(3,4-$ dihydroxyphenyl)ethylamine) is reported to reduce the porosity of cryptococcal cell walls (22). Basic adhesion of appressorium to various surfaces was not affected by MBIs, as proven in wash-off experiments where adhesion of appressoria to glass and poly-

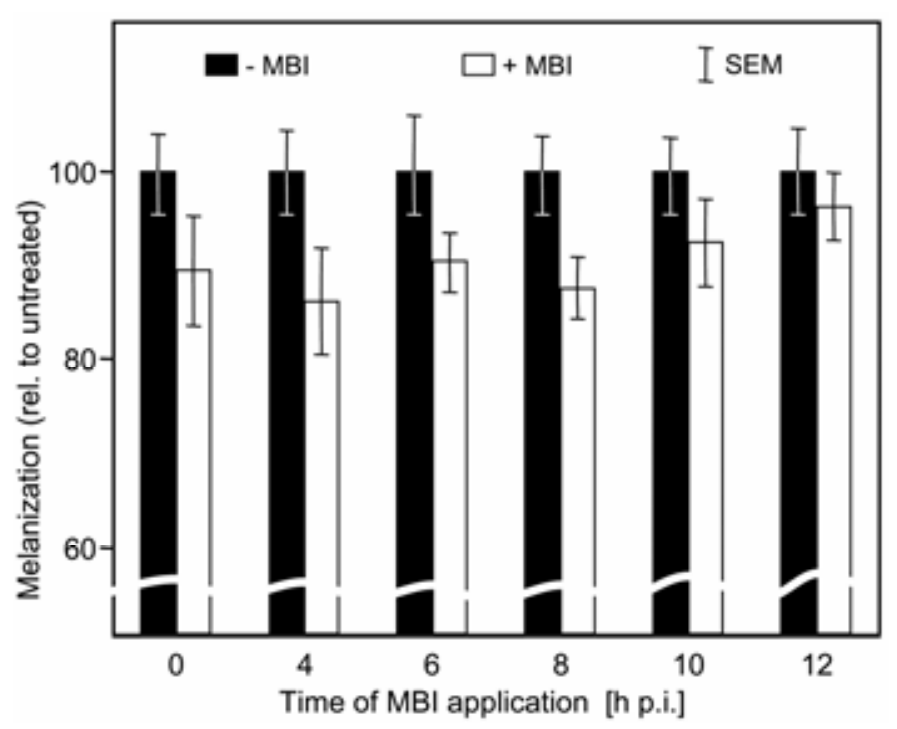

Fig. 8. Effect of application time of the melanin biosynthesis inhibitor (MBI) carpropamid on the intensity of melanin production of Venturia inaequalis germlings on polystyrene. Melanization was compared with that of untreated germlings using the image processing software ASSESS for assessing the intensity of color after $36 \mathrm{~h}$ of incubation. styrene was tested comparing MBI-treated and untreated conidia (data not shown). Evidence for a contribution of hydrostatic pressure in the infection of $V$. inaequalis is lacking and, because of the very thin character of the (leaf) cuticle to be penetrated, the involvement of physical pressure seems to be rather unlikely. Extracellular hydrolytic enzymes (RNase, DNase, acid phosphatase, and phenoloxidase) excreted by $V$. inaequalis bind with cell wall melanin $(16,17)$. This may be a means to focus the activity of these enzymes at the penetration pore, making the products of their action more available, and also may concentrate the penetrating activity of the pathogen. MARS is demonstrated to be not a part of the infection sac described by Maeda (30), Corlett et al, $(7,8)$, and Smereka et al. (40); in fact, this ring structure seems to be involved in the compartmentalization of enzymes necessary for successful penetration of the cuticle.

Biosynthesis and transport of melanin precursors as well as the incorporation of these substances into the ring structure may be a sequence of steps starting at the time of appressorium differentiation and may be visible as soon as 10 to $12 \mathrm{hpi}$. Although the physical and chemical characteristics of $V$. inaequalis melanin are similar to those of DOPA-melanin, biosynthesis of melanin has been reported to be via the DHN pathway (10). Many fungi produce melanin via the polyketide pathway (3).

Inhibitors of fungal DHN-melanin biosynthesis (MBIs) are known to differ in their mode of action. Carpropamid, fenoxanil, diclocymet, and cyclobutane carboxamide are inhibitors of the scytalone dehydratase activity (dehydratase inhibitors), whereas tricyclazole, pyroquilon, and phthalide inhibit the reduction reactions (reductase inhibitors) $(25,26,44)$. Carpropamid is a melanin biosynthesis-inhibiting antipenetrant compound largely used in rice production, which may be applied as a seed treatment, nursery-box treatment, or foliar spray (41). When applied to the seed, carpropamid not only was readily absorbed but also was translocated to different parts of the seedlings; a substantial portion of fungicide appeared to be exuded onto the leaf surface (36).

According to Gessler and Stumm (13) and Hering et al. (15), germ tubes of $V$. inaequalis may penetrate the cuticle directly without forming an appressorium. The frequency and relative importance of this potential for apple infection are unknown, as is any involvement of MARS formation in direct penetration. Nevertheless, this potential may explain why efficacy of MBIs in re-

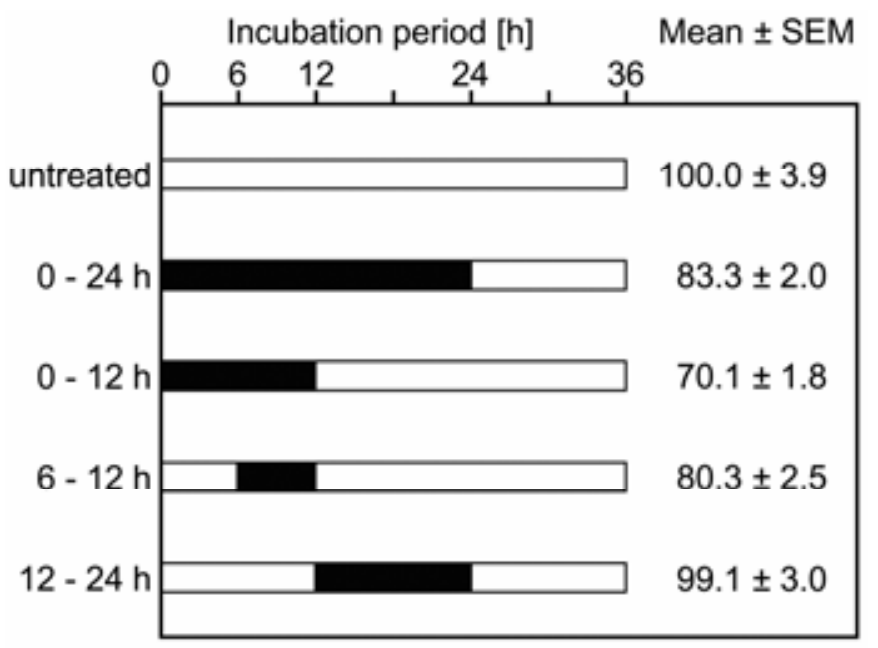

Fig. 9. Effect of incubation period of the melanin biosynthesis inhibitor (MBI) carpropamid on the intensity of melanin production of Venturia inaequalis germlings on polystyrene. Incubated spores were treated with carpropamid after 0,6 , and $12 \mathrm{~h}$ postinoculation (dark part of bars); the MBI was removed from the spores by rinsing the spots two times with tap water. Melanization was compared with that of untreated germlings using the image processing software ASSESS for assessing the intensity of coloration after $36 \mathrm{~h}$ of incubation; $\mathrm{SEM}=$ standard error of the mean. 
ducing apple scab was $<100 \%$. The higher efficacy of carpropamid compared with the other MBIs may result from induced resistance of apple leaves against $V$. inaequalis $(35,43)$.

Although RNA-mediated silencing of the trihydroxynaphthalene reductase gene $T H N$ resulted in a modified phenotype under in vitro conditions, the transformants are reported to maintain the ability to infect apple; however, the actual degree of infection was not quantified (11). In contrast, the inhibition of the melanin biosynthesis pathway using reductase inhibitors (tricyclazole or pyroquilon) and dehydratase inhibitors (carpropamid or fenoxanil) proved to be highly effective in preventing $V$. inaequalis infection. In the presence of MBIs, complementation of the pathway with the intermediate DHN restored the pathogenicity of $V$. inaequalis, supporting our hypothesis that melanin is a factor of pathogenicity as well as the DHN-type of $V$. inaequalis melanin. Fitzgerald et al. (11) restricted their statement to laboratory conditions and referred to the reduction in pathogenicity of some $V$. inaequalis mutants as described by MacHardy (27). The developmental regulation and function of MARS in host penetration by $V$. inaequalis has to be elucidated in more detail.

\section{ACKNOWLEDGMENTS}

We thank R. Pontzen, Bayer CropScience AG, Monheim, Germany, for providing carpropamid and 1,8-dihydroxynaphthalene; J. Hamacher for support in the electron microscopic investigations; and I. Neukirchen for technical assistance.

\section{LITERATURE CITED}

1. Aderhold, R. 1896. Die Fusicladien unserer Obstbäume. I. Teil. Landwirtsch. Jahrb. 25:875-914.

2. Aderhold, R, 1900. Die Fusicladien unserer Obstbäume. II. Teil. Landwirtsch. Jahrb. 29:541-588.

3. Bell, A. A., and Wheeler, M. H. 1986. Biosynthesis and function of fungal melanins. Annu. Rev. Phytopathol. 24:411-451.

4. Benyagoub, M., Benhamou, N., and Carisse, O. 1998. Cytochemical investigations of the antagonistic interaction between a Microsphaeropsis sp. (isolate P130A) and Venturia inaequalis. Phytopathology 88:605-613.

5. Butler, M. J., Day, A. W., Henson, J. M., and Money, N. P. 2001. Pathogenic properties of fungal melanins. Mycologia 93:1-8.

6. Butler, M. J., and Lachance, M. A. 1986. Quantitative binding of azure A to melanin of the black yeast Phaeococcomyces. Exp. Mycol. 10:166-170.

7. Corlett, M., and Chong, J. 1977. Ultrastructure of the appressorium of Spilocea pomi. Can. J. Bot. 55:5-7.

8. Corlett, M., Chong, J., and Kokko, E. G. 1976. The ultrastructure of the Spilocea state of Venturia inaequalis in vivo. Can. J. Microbiol. 22:11441152.

9. De Jong, J. C., McCormack, B. J., Smirnoff, N., and Talbot, N. J. 1997. Glycerol generates turgor in rice blast. Nature 389:244-245.

10. El Bassam, S., Benhamou, N., and Carisse, O. 2002. The role of melanin in the antagonistic interaction between the apple scab fungus Venturia inaequalis and Microsphaeropsis ochracea. Can. J. Microbiol. 48:349358.

11. Fitzgerald, A., van Kan, J. A. L., and Plummer, K. M. 2004. Simultaneous silencing of multiple genes in the apple scab fungus, Venturia inaequalis, by expression of RNA with chimeric inverted repeats. Fungal Gen. Biol. 41:963-971.

12. Gadoury, D. M., and MacHardy, W. E. 1986. Forecasting ascospore dose of Venturia inaequalis in commercial apple orchards. Phytopathology 76:112-118.

13. Gessler, C., and Stumm, D. 1984. Infection and stroma formation by Venturia inaequalis on apple leaves with different degrees of susceptibility to scab. Phytopathol. Z. 110:119-126.

14. Henson, J. M., Butler, M. J., and Day, A. W. 1999. The dark side of the mycelium: melanins of phytopathogenic fungi. Annu. Rev. Phytopathol. 37:447-471.

15. Hering, O., Zinkernagel, V., and Bartscherer, H.-C. 1993. Rasterelektronenmikroskopische Untersuchungen zum Infektionsverhalten von Venturia inaequalis (Cooke) Aderh. auf Blättern unterschiedlich resistenter Apfelsorten. Z. Pflanzenkrankh. Pflanzenschutz 100:379-388.

16. Hignett, R. C., and Kirkham, D. S. 1967. The role of extracellular melanoproteins of Venturia inaequalis in host susceptibility. J. Gen. Microbiol. 48:269-275.

17. Hignett, R. C., Roberts, A. L., and Carder, J. H. 1979. The properties and extracellular enzymes of Venturia inaequalis and their association with loss of virulence of the fungus in culture. J. Gen. Microbiol. 110:67-75.

18. Hignett, R. C., Roberts, A. L., and Carder, J. H. 1984. Melanoprotein and virulence determinants of Venturia inaequalis. Physiol. Plant Pathol. 24:321-330.

19. Howard, R. J., and Ferrari, M. A. 1989. Role of melanin in appressorium function. Exp. Mycol. 13:403-418.

20. Howard, R. J., and Valent, B. 1996. Breaking and entering: Host penetration by the fungal rice pathogen Magnaporthe grisea. Annu. Rev. Microbiol. 50:491-512.

21. Ishii, H., Park, P., Müller, M., Adachi, Y., Kanematsu, S., Ieki, H., and Umemoto, S. 1998. Infection behavior of Venturia nashicola and supposed involvement of cell-wall degrading enzymes in the pathogenesis of Japanese pear. Pages 291-292 in: Molecular Genetics of Host-Specific Toxins in Plant Disease. K. Kohmoto and O. C. Yoder, eds. Kluwer Academic Publishers, Dordrecht, The Netherlands.

22. Jacobson, E. S., and Ikeda, R. 2005. Effect of melanization upon porosity of the cryptococcal cell wall. Med. Mycol. 43:327-333.

23. Koller, W., Parker, D. M., and Becker, C. M. 1991. Role of cutinase in the penetration of apple leaves by Venturia inaequalis. Phytopathology 81:1375-1379.

24. Kubo, Y., and Furusawa, I. 1986. Localization of melanin in appressoria of Colletotrichum lagenarium. Can. J. Microbiol. 32:280-282.

25. Kurahashi, Y. 2001: Melanin biosynthesis inhibitors (MBIs) for control of rice blast. Pestic. Outlook 12:32-35.

26. Kurahashi. Y., Sakawa, S., Kinhara, T., Tanaka, K., and Kagabu, S. 1997. Biological activity of carpropamid (KTU 3616) - a new fungicide for rice blast disease. J. Pestic. Sci. (Int. ed.) 22:108-112.

27. MacHardy, W. E. 1996. Apple Scab, Biology, Epidemiology and Management. American Phytopathological Society, St. Paul, MN.

28. MacHardy, W. E., Gadoury, D. M., and Gessler, C. 2001. Parasitic and biological fitness of Venturia inaequalis: Relationship to disease management strategies. Plant Dis. 85:1036-1051.

29. MacHardy, W. E., and Jeger, M. 1983. Integrating control measures for the management of primary apple scab, Venturia inaequalis (Cke.) Wint. Prot. Ecol. 5:103-125.

30. Maeda, K. M. 1970. An ultrastructural study of Venturia inaequalis (Cke.) Wint. infection of Malus host. M.Sc. thesis, Purdue University, Lafayette, IN.

31. Meier, U., ed. 1997. Growth Stages of Mono- and Dicotyledonous Plants. Federal Biological Research Centre for Agriculture and Forestry, Blackwell Wissenschafts-Verlag, Berlin.

32. Mills, W. D., and LaPlante, A. A. 1951. Diseases and insects in the orchard. Cornell Ext. Bull. 711, Ithaca, NY.

33. Müller, M. W., and Ishii, H. 1997. Esterase activity from Venturia nashicola: Histochemical detection and supposed involvement in the pathogenesis of scab on Japanese pear. J. Phytopathol. 145:473-477.

34. Nusbaum, C. J., and Keitt, G. W. 1938. A cytological study of hostparasite relations of Venturia inaequalis on apple leaves. J. Agric. Res. (Washington, D.C.) 56:595-618.

35. Ortega, F., Steiner, U., and Dehne, H. W. 1998. Induced resistance to apple scab: Microscopic studies on the infection cycle of Venturia inaequalis (Cke.) Wint. J. Phytopathol. 146:399-405.

36. Rohilla, R., Singh, U. S., and Singh, R. L. 2001. Uptake and translocation of carpropamid in rice (Oryza sativa L.). Pest Manage. Sci. 57:239-247.

37. Rossi, V., Giosue, S., and Bugiani, R. 2003. A model simulating deposition of Venturia inaequalis ascospores on apple trees. EPPO Bull. 33:407414.

38. Rossi, V., Ponti, I., Marinelli, M., Giosue, S., and Bugiani, R. 2001. Environmental factors influencing the dispersal of Venturia inaequalis ascospores in the orchard air. J. Phytopathol. 149:11-19.

39. Rotem, J. 1994. The Genus Alternaria: Biology, Epidemiology, and Pathogenicity. American Phytopathological Society, St. Paul, MN.

40. Smereka, K. J., MacHardy, W. E., and Kausch, A. P. 1987. Cellular differentiation in Venturia inaequalis ascospores during germination and penetration of apple leaves. Can. J. Bot. 65:2549-2561.

41. Takino, T., Araki, Y., and Kabori, I. 1994. Method for GLC determination of residues of carpropamid in rice grain and straw. Nihon Bayer Agrochem KK, Yuki Research Centre, Environmental Science Research, Japan, Report No. NR1296 (ESR/ENG).

42. Tanabe, K., Park, P., Tsuge, T., Kohmoto, K., and Nishimura, S. 1995. Characterization of the mutants of Alternaria alternata Japanese pear pathotype deficient in melanin and their pathogenicity. Ann. Phytopathol. Soc. Jpn. 61:27-33.

43. Thieron, M., Pontzen, R., and Kurahashi, Y. 1998. Carpropamid: A rice fungicide with two modes of action. Bayer Pflanzenschutznachrichten 51:257-277.

44. Tsuji, G., Takeda, T., Furusawa, I., Horino, O., and Kubo, Y. 1997. Carpropamid, an anti-rice blast fungicide, inhibits scytalone dehydratase activity and appressorial penetration in Colletotrichum lagenarium. 
Pestic. Biochem. Physiol. 57:211-219.

45. Turner, M. L., MacHardy, W. E., and Gadoury, D. M. 1986. Germination and appressorium formation by Venturia inaequalis during infection of apple seedling leaves. Plant Dis. 70:658-660.

46. Valsangiacomo, C., and Gessler, C. 1988. Role of the cuticular membrane in ontogenic and Vf-resistance of apple leaves against Venturia inaequalis. Phytopathology 78:1066-1069.

47. Valsangiacomo, C., Wagner, K., Stadler, B., Ruckstuhl, M., ManiniGessler, P., Michel, M., and Gessler, C. 1989. Aspects of host resistance and pathogenesis in the interaction between Venturia inaequalis and apple leaves. Pages 191-204 in: Integrated Control of Pome Fruit Diseases. C.
Gessler, D. J. Butt, and B. Koller, eds. Vol. II., IOBC-WPRS-Bull. XII/6. 48. Wiltshire, S. P. 1915. Infection and immunity studies on the apple and pear scab fungus (Venturia inaequalis and V. pirina). Ann. Appl. Biol. 1:335-350.

49. Wolkow, P. M., Sisler, H. D., and Vigil, E. L. 1983. Effect of inhibitors of melanin biosynthesis on structure and function of appressoria of Colletotrichum lindemuthianum. Physiol. Plant Pathol. 22:55-71.

50. Woloshuk, C. P., Sisler, H. D., Tokousbalidis, C. M., and Dutky, S. R. 1980. Melanin biosynthesis in Pyricularia oryzae: Site of tricyclazole inhibition and pathogenicity of melanin-deficient mutants. Pestic. Biochem. Physiol. 14:256-264. 